\title{
The ups and downs of information jobs
}

Last update: 3 March 2020

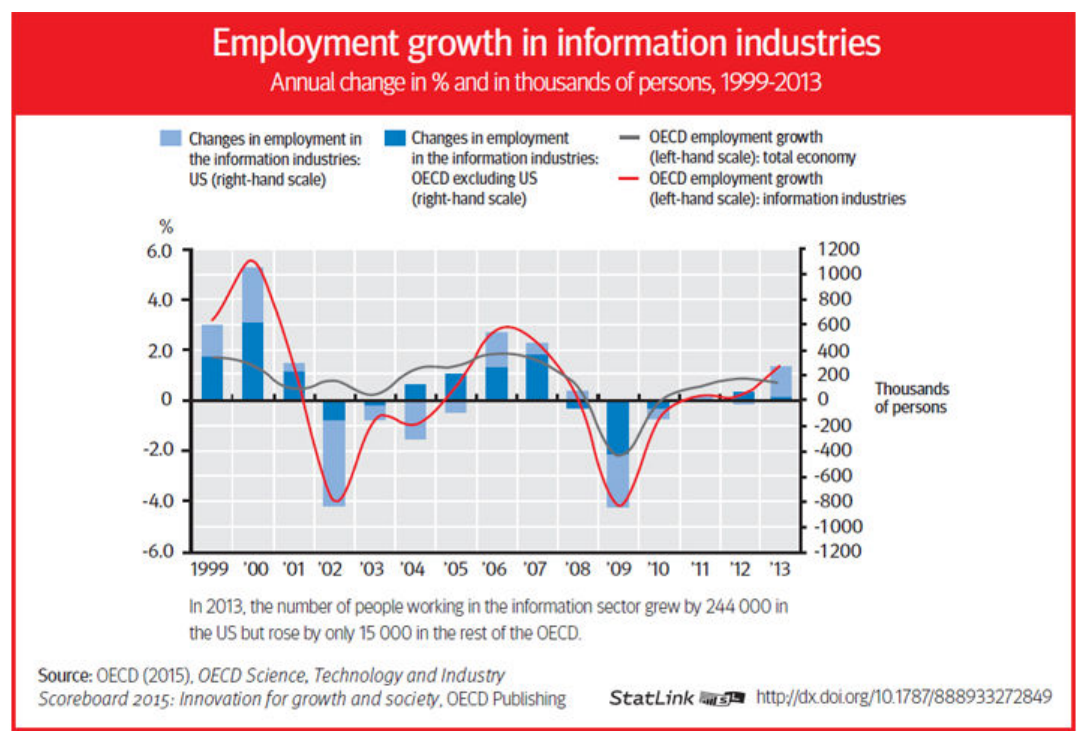

http://dx.doi.org/10.1787/888933272849

Publishing, telecommunications, the audiovisual industry and broadcasting taken together are an important source of value-added growth in OECD countries despite accounting for less than $4 \%$ of total OECD employment. This "information sector" covers a wide range of activities, from computer and optical manufacturing to communications services.

Between 1995 and 2013 employment in the information industries grew by about $15 \%$ in OECD countries, marginally less than the growth in total employment during the same period. However, employment in the information sector has been susceptible to high volatility over the business cycle since 1995.

For example, during the 2008-09 financial crisis, OECD information industry employment fell by $4 \%$, compared with $2 \%$ for total employment, shedding over 800000 jobs. This drop was the first since the bursting of the dot-com bubble in 2000 . The US now accounts for about $30 \%$ of OECD employment in the information industries, from a peak of about $34 \%$ in 2001, and has been a main driver of changes in OECD information sector employment recorded over recent years.

See www.oecd.org/sti and www.oecd.org/fr/sti/dep-ministerial-2016.htm 